\title{
Tổ chức thi công hệ ván khuôn di động cho giếng điều áp
}

\author{
Nguyễn Văn Mạnh ${ }^{1}$ \\ ${ }^{1}$ Khoa cơ khí - Trường đại học xây dựng Hà nội, 55 Giải Phóng, Hai Bà Trưng, Hà Nội
}

\begin{tabular}{ll}
\hline TỪ KHOÁ & TÓM TẮT \\
\cline { 2 - 3 } Giếng điều áp & Giếng điều áp là hạng mục thi công quan trọng đối với mỗi nhà máy thủy điện. Việc thi công các công \\
Ván khuôn di động & trình thuỷ điện là không giống nhau, phụ thuộc vào điều kiện đia hình, điều kiện tự nhiên. Công nghệ thi \\
Thưy điện & công và phương pháp thi công luôn là yếu tố quan trọng nhất của công trình, quyết định chất lượng, tiến \\
& độ và chi phí đầu tư xây dựng ở mỗi dự án thủy điện. Tác giả giới thiệu qui trình tổ chức thi công hệ \\
thống ván khuôn di động phục vụ thi công giếng điều áp trong các công trình thủy điện nhằm mục tiêu \\
kép là đảm bảo chất lượng - tiến độ và chi phí đồng thời phù hợp với điều kiện công nghệ chế tạo của \\
Việt Nam.
\end{tabular}

\section{KEYWORDS}

Surge tank

Mobile formwork system

Hydroelectric

\begin{abstract}
Surge Tank is an important construction item for each hydroelectric power plant. The construction of hydroelectric projects is different, depending on topographical and natural conditions. Construction technology and construction method are always the most important factor of the project, determining the quality, progress and cost of construction investment in each hydropower project. The author introduces the process of organizing the construction of a mobile formwork system for the construction of surge tank in hydroelectric projects with the dual goals of ensuring quality - progress and cost and at the same time being suitable for the project manufacturing technology in Vietnam.
\end{abstract}

\section{Giới thiệu}

Đất nước ta đang ở trong thời đại công nghiệp hoá hiện đại hoá đất nước, nhu cầu sử dụng điện năng để phục vụ sản xuất, sinh hoạt của con người ngày càng tăng. Đặc biệt với mạng lưới sông ngòi dày đặc, việc chinh phục dòng nước để biến tài nguyên nước thành điện năng ngày càng được sự thu hút, quan tâm của các cơ quan quản lý nhà nước và nhà đầu.

Buồng (bể) điều áp hay giếng điều áp thường được đặt ở giữa đường dẫn có áp, trong đường ống dẫn nước tới turbin, giếng điều áp thì được xây dựng ngầm trong lòng đất, còn buồng (bể) điều áp thì được xây nổi trên mặt đất. Trong đường ống dẫn nước tới turbin của trạm thuỷ điện, ngoài áp lực nước thông thường còn chịu thêm áp lực va khi đóng mở turbin.Trị số nước va càng lớn thì đường ống càng dài và ngược lại. Nếu tạo ra một mặt thoáng ở một vị trí nào đó trên đường dẫn nước thì áp lực nước va được giải phóng và từ vị trí này đến thượng lưu đường ống sẽ không chịu áp lực nước va nữa. Buồng điều áp chính là bộ phận tạo ra mặt thoáng đó. Do đó giếng điều áp hay buồng điều áp có tác dụng giữ cho đường ống dẫn nước ở phía trước nó khỏi bị áp lực nước va và làm giảm áp lực ở phần đường ống dẫn nước từ tháp vào turbin hay nói cách khác buồng bể (giếng) có tác dụng điều tiết áp lực dòng chảy trên đường ống áp lực trong những trường hợp cửa van trước turbin phát điện đóng mở đột ngột [1]. Trên thế giới cũng có rất nhiều tài liệu nghiên cứu về công dụng, chức năng và phương án nâng cao hiệu quả của giếng điều áp [2 - 4]
Giếng điều áp thường có kết cấu dạng trụ tròn, có đường kính từ (12 $30) \mathrm{m}$, cao trình thường từ $(60-80) \mathrm{m}$, và chiều dày lớp bảo vệ bê tông của giếng thường từ $(0,50-0,80) \mathrm{m}$. Hạng mục thi công giếng điều áp là rất quan trọng đối với mỗi nhà máy thủy điện. Việc thi công các công trình thuỷ điện là không giống nhau, phụ thuộc vào điều kiện đia hình, điều kiện tự nhiên. Công nghệ thi công và phương pháp thi công luôn là yếu tố quan trọng nhất của công trình quyết định chất lượng, tiến độ và chi phí đầu tư xây dựng ở mỗi dự án thủy điện.

Ván khuôn là kết cấu chuyên dụng, đảm bảo tạo ra hình dạng yêu cầu của kết cấu giếng điều áp, đồng thời ván khuôn chiếm khoảng (25 - 40) \% tổng chi phí dự án và gần $60 \%$ thời gian thi công bê tông [2]. Từ đó việc phân tích, lựa chọn, thiết kế hệ thống ván khuôn thi công đáp ứng được yêu cầu trong công tác tổ chức thi công lớp áo thành giếng điều áp, đảm bảo tiến độ thi công nhanh, chi phí hợp lý và an toàn là việc hết sức cần thiết ở mỗi dự án thi công thủy điện. Mục đích của bài báo này là giới thiệu về qui trình tổ chức thi công hệ thống ván khuôn di động phục vụ thi công giếng điều áp, trong điều kiện công nghệ chế tạo thiết bị, trình độ tổ chức thi công tại Việt Nam.

\section{Hệ thống ván khuôn di động}

Công tác ván khuôn là một trong những công tác quan trọng của quá trình thi công, vì vậy việc lựa chọn phương án ván khuôn hợp lý sẽ tạo điều kiện cho quá trình thi công được dễ dàng, đảm bảo chất lượng và góp phần vào hoàn thành tiến độ thi công. Hệ thống ván khuôn di động có các loại sau: 


\subsection{Ván khuôn trượt}

Thi công bằng ván khuôn pha trượt là dùng các kích chuyên dụng đẩy ván khuôn trượt lên theo mặt bê tông cùng đồng thời với các công việc lắp đặt cốp thép, đổ bê tông vào cốp pha để tạo hình kết cấu bê tông cốp thép cần thi công. Công nghệ ván khuôn trượt được thi công lần đầu tiên trên thế giới để đổ bê tông xilô vào năm 1903 tại Mỹ, sau đó tại Liên Xô cũ vào năm 1924, ở Đức vào năm 1931... Ở Việt Nam, công nghệ ván khuôn trượt được áp dụng lần đầu tiên vào năm 1973 tại công trường K3 để thi công ống khói của nhà máy nhiệt điện Ninh Bình cao 60 m. [ 2].

Công nghệ ván khuôn trượt ngày càng phát triển và hoàn thiện, nó không chỉ là một công nghệ độc lập mà nó còn là một công nghệ tiên tiến kết hợp với các công nghệ khác để thi công trên cao một cách co hiệu quả.Hiên nay ở Việt Nam đang áp dụng rất nhiều công nghệ ván khuôn trượt để xây dựng các toà nhà cao tầng, các công trình thi công ống khói, tháp nước, giếng điều áp trên khắp cả nước.

\subsection{Ván khuôn leo}

Ván khuôn tự leo là một dạng ván khuôn được nâng chuyển lên cao theo chu kì (gọi là leo) và thường được cấu tạo từ cốp pha tấm lớn. Toàn bộ ván khuôn hay một đoạn ván khuôn được nâng lên cao theo từng chu kì. Ván khuôn leo có hai hình thức rất giống ván khuôn trượt nhưng sử dụng kích nâng. Ngoài ra, nó còn được nâng bằng cáp tự kéo lên, cáp thông qua các con đội hay trụ đỡ, theo hình thức co rút để dịch chuyển lên cao và tự quay lật lên có sự hỗ trợ của cần trục. Có các phương pháp di chuyển tấm cốp pha như sau: phương pháp leo bằng tời nâng, phương pháp leo bằng kích thủy lực, phương pháp leo bằng cần trục.

Công nghệ ván khuôn leo đã được nhiều công ty, đơn vị xây dựng áp dụng tại nhiều tòa nhà cao tầng trên thế giới và tại Việt Nam. Đây là những thiết bị, công nghệ thi công có hiệu quả cao, phù hợp với xu thế công nghệ mới, mang lại lợi thế rất lớn cho doanh nghiệp trong lĩnh vực thi công xây lắp, đặc biệt hiệu quả đối với thi công các phần vách trước, độc lập với phần sàn, thường áp dụng đối với phần: xilo, trụ cầu, lõi thang máy trong nhà cao tầng, vách nhà cao tầng, các công trình có chiều cao lớn.

Công nghệ ván khuôn leo được chế tạo và sử dụng dựa trên nguyên lý: Sau một chu kỳ đổ bê tông, cường độ bê tông đạt đến giá trị cho phép tháo ván khuôn sẽ tiến hành chuyển ván khuôn lên một đoạn khác (leo lên một đoạn khác). Việc thi công bằng ván khuôn leo phụ thuộc vào tính chất, tiến độ đổ bê tông của công trình, nhiệt độ môi trường, tốc độ đổ bê tông, cường độ bê tông và chi phí thi công hệ ván khuôn. Ngoài việc đổ bê tông cho các kết cấu thẳng đứng thì ván khuôn leo có thể thi công với kết cấu có độ nghiêng nhất định nên công nghệ ván khuôn leo được sử dụng đa dạng.

\section{Lựa chọn và tổ chức thi công ván khuôn giếng điều áp}

\subsection{Lựa chon phương án thi công ván khuôn}

Phương án thi công sử dụng ván khuôn trượt là một phương pháp được thực hiện theo một quy trình công nghệ chặt chẽ và có tổ chức cao, thể hiện đầy đủ và rõ nét các đặc trưng của phương pháp thi công theo dây truyền trong xây dựng. Ưu điểm của phương pháp này là có khả năng tinh chỉnh tốt, tốc độ thi công nhanh. Sử dụng ván khuôn trượt đạt được hiệu quả cao theo xu hướng công nghiệp hoá, bởi công tác thi công được tố chức theo dây truyền liên hoàn tốc độ cao. Ván khuôn trượt là loại thiết bị hoàn chỉnh, cấu trúc phức tạp, khi trượt phải tuân thủ nghiêm ngặt tốc độ nâng để đảm bảo cho vữa bê tông thực hiện quá trình ninh kết trong ván khuôn theo yêu cầu quy định, không để cho bê tông tách lớp đồng thời cũng không để bê tông sụt xuống gây nguy hại và phá hoại cho công trình. Tuy nhiên đòi hỏi về trình độ kỹ thuật và tổ chức cao. Đối với phương án thi công bằng ván khuôn trượt công tác tính toán, thiết kế phục vụ thi công gặp nhiều thuận lợi bởi thi công bằng ván khuôn trượt dùng để thi công giếng điều áp hệ thống ván khuôn được nâng lên cùng với quá trình đổ bê tông, với loại ván khuôn này phù hợp thi công công trình có mặt thoáng ở bên trong, bên ngoài hoặc cả 2 phía trong và ngoài, với giếng điều áp có mặt thoáng bên trong nên phương án này rất khả thi.

Đối với phương án thi công bằng ván khuôn leo, hệ ván khuôn di chuyển đến vị trí đổ bê tông, sau đó chờ bê tông đông cứng đủ cường độ rồi di chuyển đến vị trí mới để thực hiện chu kỳ đổ tiếp theo. Loại này thời gian thi công lâu hơn ván khuôn trượt. Phương pháp đổ bê tông theo chu kỳ này ván khuôn di chuyển lên theo mỗi đoạn đổ bê tông, mỗi chu kỳ đổ bê tông không lớn lắm thường từ (1,5 - 2) m. Khi lắp dựng xong côt thép cho một chu kỳ đổ bê tông thì ván khuôn được di chuyển đến nhờ hệ thống tời kéo, hoặc xy lanh thuỷ lực. Thời gian để vữa bê tông ninh kết sẽ tiến hành công tác thi công cốt thép cho đoạn đổ tiếp theo.

\subsection{Tổ chức thi công giếng điều áp theo phương án ván khuôn leo}

\subsubsection{Cấu tạo hệ thống ván khuôn leo thi công giếng điều áp}

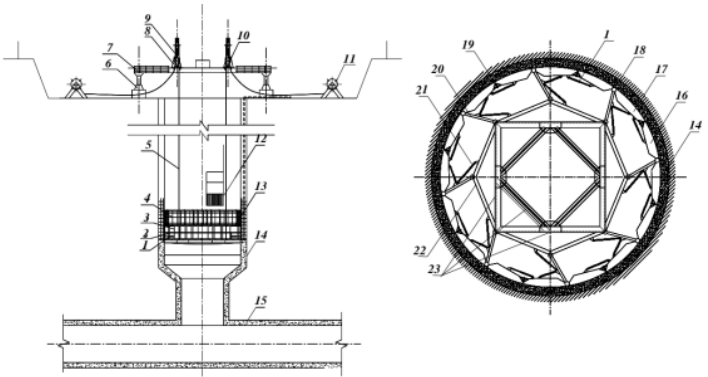

Hình 1.Hệ thống ván khuôn thi công giếng điều áp.

1: Hệ thống kích co duỗi tấm ván khuôn tầng dưới; 2: Hệ thống khung ; 3: Hệ ván khuôn; 4: Sàn sao tác; 5: Cáp nâng; 6: Trụ đỡ hệ thống khung treo; 7: Cụm dầm treo hệ thống ván khuôn miệng giếng; 8: Khung tời thủy lực; 9: Xy lanh thủy lực: 10: Cụm khóa cáp; 11: Tang thu hồi cáp nâng; 12: Thang nâng thi công; 13: Hệ thống kích co duỗi tấm ván khuôn tầng trên; 14: Kết cấu thành giếng điều áp; 15: Đường hầm dẫn nước; 16, 17: Tấm ván khuôn thành phần; 18: Điểm nối các tấm ván khuôn thành phần; 19: Ty 
ren liên kết, co duỗi tấm ván khuôn thành phần; 20: Thanh chống; 21: Xy lanh co duỗi thanh chống; 22: Thanh bao khung chính; 23: Khung chính hệ ván khuôn
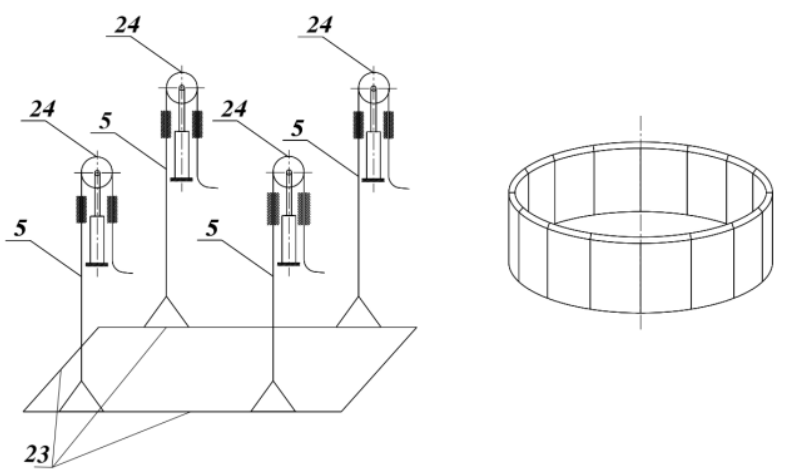

Hình 2. Sơ đồ mắc cáp và hình khối ván khuôn.

24: Cụm pu ly đỉnh nâng hạ hệ ván khuôn giếng điều áp; 23: Hệ thống khung chính ván khuôn;

Cấu tạo hệ thống ván khuôn thi công giếng điều áp theo phương án ván khuôn leo được mô tả trong Hình 1 , và sơ đồ mắc cáp và hình khối ván khuôn được mô tả trong Hình 2. Công tác tổ chức thi công ván khuôn giếng điều áp tuân thủ theo trình tự sau:

\subsubsection{Giai đoạn 1: Chế tạo, vận chuyển}

Ván khuôn được chế tạo thành từng tấm, đã được hàn và gia công vòng găng tại nhà máy sản xuất, khi vận chuyển cần đặt đứng ván khuôn, dựng sát các tấm vào nhau có dụng cụ kê để chống bị xô lệch khi vận chuyển dẫn đến ván khuôn bị cong, vênh.

Hệ thống khung chính được vận chuyển từng thanh dời, trước khi xuất xưởng cần kiểm tra lắp ráp thử. Từng bộ phận, dầm ngang, thanh trụ được vận chuyển đến công trường rồi tùy thuộc vào bề dày của kết cấu cần thi công để lắp ráp vị trí cho phù hợp.

Dầm tia, thanh chống được gia công từ nhà máy sau đó được vận chuyển đến công trình để lắp ráp.Sàn thao tác được vận chuyển thành từng tấm như vận chuyển cốp pha, khi đến công trường vừa lắp ráp vừa tiến hành gia công.

Máy móc được vận chuyển đến công trường phải thực hiện công tác bảo dưỡng kiểm tra trước khi đưa vào sử dụng. Các thiết bị thủy lực được vận chuyển dời đến công trường, các đường ống sẽ được lắp đặt tại công trình. Ngoài ra các thiết bị và dụng cụ đo kèm theo cũng được kiểm tra trong thời điểm kiểm tra hệ thống thủy lực.

\subsubsection{Gia đoạn 2: Tổ chức lắp đặt}

Sau công tác gia công lắp đặt cốt thép nhịp ván khuôn trượt thứ 1 hoàn thành, công tác thi lắp đặt hệ thống ván khuôn được triển khai tại hiện trường. Trình tự lắp đặt được tiến hành bao gồm: Tổ chức lắp đặt toàn bộ thiết bị trên miệng giếng điều áp (Cụm dầm treo hệ thống ván khuôn, cụm thu hồi cáp, hệ thống puly, hệ thống khóa cáp), Lắp đặt hệ thống khung chính, thanh bao khung chính, thanh chống liên kêt vào các tấm ván khuôn đã chế tạo sẵn, lắp đặt hệ thống xy lanh thủy lực, hệ thống sàn thao tác...

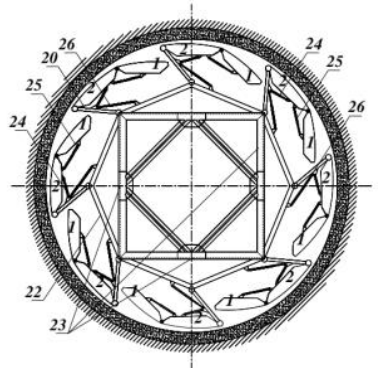

Hình 3. Tổ chức lắp đặt - duỗi hệ thống giai đoạn 1 .

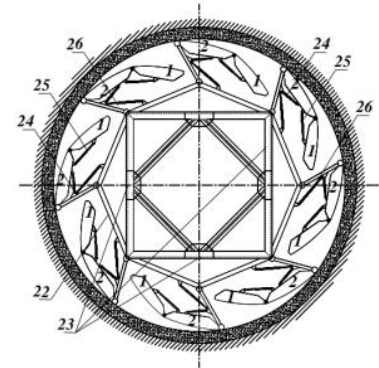

Hình 4. Tổ chức lắp đặt - duỗi hệ thống gian đoạn 2
20: Thanh chống; 22: Thanh bao khung chính; 23: Khung chính hệ ván khuôn 24: Xy lanh co duỗi tấm ván khuôn số 2; 25: Xy lanh co duỗ tấm ván khuôn số 1; 26: Xy lanh co duỗi thanh chống

Khi toàn bộ hệ thống chi tiết đã được lắp dựng và định hình sơ bộ, công tác tinh chỉnh hệ thống được tiến hành theo 4 công đoạn:

Công đoạn 1 (Hình 3): Mỗi tấm ván khuôn thành phần nhỏ được tách và đánh số thành các tấm ván khuôn bộ phận, mỗi tấm ván khuôn bộ phận được điều khiển co duỗi bởi 02 xy lanh (01 phía trên, 01 xy lanh phía dưới). Ở giai đoạn này tổ hợp xy lanh điều khiển thanh chống duỗi ra hết hành trình, thanh chống bắt đầu tiếp xúc vào sát thành hệ cốt thép đã được gia công.

Công đoạn 2 (Hình 4): Cụm xy lanh điều khiển tấm ván khuôn số 2 và số 1 bắt đầu duỗi ra.

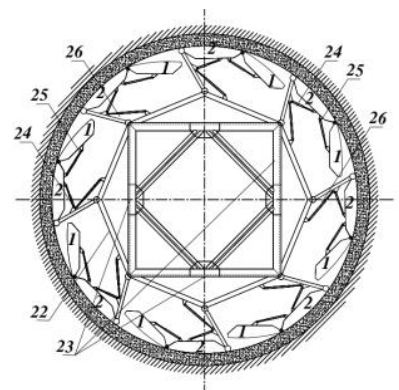

Hình 5. Tổ chức lắp đặt - duỗi hệ thống giai đoạn 3.

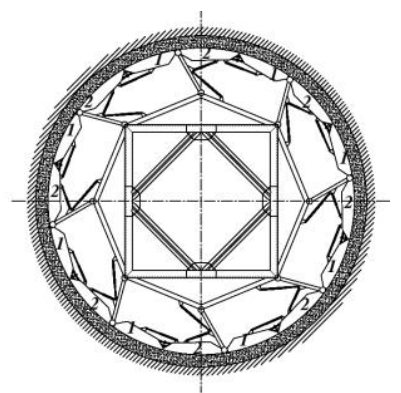

Hình 6. Tổ chức lắp đặt - duỗi hệ thống giai đoạn 4.
Công đoạn 3 (Hình 5): Cụm xy lanh điều khiển tấm ván khuôn số 2 duỗi đến khi chạm tới vị trí định vị, và tiếp tục điều khiển để cụm xy lanh điều khiển tấm ván khuôn số 1 duỗi hết hành trình chạm tới vị trị định vị.

Công đoạn 4 (Hình 6): Khi tất cả các tấm ván khuôn chạm tới vị trí định vị, bắt đầu quá trình vận hành thử tải và tinh chỉnh.

Tổ chức vận hành thử tải hệ thống sau khi lắp đặt toàn bộ chi tiết, tinh chỉnh hệ thống ván khuôn, đưa hệ thống ván khuôn ép sát vào cốt thép, chuẩn bị công tác thi công bê tông. 


\subsubsection{Giai đoạn 3: Tổ chức co duỗi và di chuyển (hình 3)}

Tiến hành co duỗi hệ thống ván khuôn ngay sau khi kết thúc thời gian đổ bê tông trong khoảng từ (24 - 36) giờ. Trình tự co duỗi hệ thống ván khuôn được thực hiện ngược lại với quá trình duỗi hệ thống, các cụm xy lanh điều khiển tấm ván khuôn số 1 được vận hành co lại, sau đó tới các cụm xy lanh điều khiển tấm ván khuôn số 2 , tới hệ thống xy lanh thanh chống co để khép kín hệ ván khuôn. Kết thúc quá trình co.

Hệ thống ván khuôn được đưa tới vị trí thi công mới, sau khi đốt thi công tiếp theo kết thúc quá trình gia công cốt thép. Hệ thống ván khuôn, kèm sàn thao tác được di chuyển đều các góc bởi cụm cáp treo được kéo nhờ cụm thu cáp phía trên miệng giếng. Khi hệ thống tới vị trí thi công mới, được đảm bảo an toàn bởi cụm khóa cáp.

\subsubsection{Giai đoạn 4: Tháo dỡ hệ thống ván khuôn}

Tháo dỡ ván khuôn là công tác quan trọng, khi kết thúc toàn bộ quá trình thi công, hệ thống được tháo dỡ theo trình tự ngược với quá trình lắp đặt. Khi kết thúc dự án, hệ thống được vệ sinh, bảo dưỡng trước khi đưa vào kho.

\section{Kết Luận}

Điện năng là một mấu chốt thúc đẩy sự phát triển và hội nhập kinh tế toàn cầu của đất nước. Chinh phục dòng nước để mang tới ánh sáng và năng lượng tới vùng sâu, vùng xa, vùng biển đảo, phục vụ cho công cuộc đổi mới đất nước là vấn đề vẫn còn thời sự. Các công trình thủy điện vẫn thuộc danh mục các công trình trọng điểm quốc gia, do đó lựa chọn phương án, tổ chức thi công phù hợp sẽ thúc đẩy quá trình thi công đảm bảo chất lượng, tiến độ, đạt mục tiêu kép chất lượng và giá thành. Công tác ván khuôn chiếm tỷ trọng lớn về chi phí đầu tư, tiến độ trong thi công xây dựng giếng điều áp trong nhà máy thủy điện, thiết kế hệ thống ván khuôn thi công đáp ứng được yêu cầu trong công tác tổ chức thi công lớp áo thành giếng điều áp, đảm bảo tiến độ thi công nhanh, chi phí hợp lý và an toàn là việc hết sức cần thiết ở mỗi dự án.

\section{Tài liệu tham khảo}

[ 1]. Đỗ Văn Chiêu, Hoàng Đình Dũng, Nguyễn Duy Hạnh, Huỳnh Tấn Lượng, Phan Kỳ Nam, Lê Gia Tài, Hoàng Văn Thắng, Sổ tay công trình thủy lợi, Nhà xuất bản nông nghiệp, 2006.

[2]. Ghulam Nabi, Habib-ur-Rehman, Muhammad Kashif and Muhammad Tariq, "Hydraulic Transient Analysis of Surge Tanks: Case Study of Satpara and Golen Gol Hydropower Projects in Pakistan," Pak. J. Engg. \& Appl. Sci, vol. 8, pp. 34-48, 2011.

[ 3]. Ramesh Kannan, Helen Santhi, "Constructability Assessment of Climbing Formwork Systems Using Building Information Modeling," Procedia Engineering, vol. 64, no. 14, p. 1129, 2013, doi: 10.1016/j.proeng.2013.09.191.

[4]. Abdulghani RAMADAN, Hatem MUSTAFA, "Surge Tank Design Considerations for Controlling Water Hammer Effects at Hydro-electric Power Plants," University Bulletin, Vols. 3-2013, no. 15, p. 147, 2013.

[ 5]. Wolfgang Richter, Gerald Zenz, Josef Schneider, Helmut Knoblauch, "Surge tanks for high head hydropower plants - Hydraulic layout - New developments," Geomechanics and Tunnelling 8 (2015), vol. 8, no. 1, p. 60, 2015, doi: 10.1002/geot.201400057.

[ 6]. Bùi Mạnh Hùng, Công nghệ cốp pha trượt xây dựng nhà cao tầng - Nhà xuất bản xây dựng, 2005. 